\title{
Obstructive oligospermia: the role of interventional radiology in its diagnosis and treatment
}

\author{
Antonio Catelli ${ }^{1 \mathrm{~A}, \mathrm{~B}, \mathrm{E}}$, Antonio Corvino ${ }^{2 \mathrm{~A}, \mathrm{~B}, \mathrm{C}, \mathrm{D}, \mathrm{E}, \mathrm{E}, \mathrm{G}, \mathrm{G}}$, Mario Quarantelli ${ }^{\mathrm{B}}$, Piero Venetucci ${ }^{1 \mathrm{~B}}$ \\ 'Department of Advanced Biomedical Sciences, University Federico II of Naples (UNINA), Naples, Italy \\ 2Department of Motor Science and Wellness, University of Naples “Parthenope", Naples, Italy
}

\section{Abstract}

Purpose: According to the latest World Health Organization guidelines (2010), oligo-sperm it is due to a sperm concentration of less than $15 \mathrm{million} / \mathrm{ml}$ of seminal fluid. The cause can be obstructive and non-obstructive. Interventional radiology allows diagnosis and, in some cases, minimally invasive treatment.

\begin{abstract}
Case presentation: A 28-year-old man with oligospermia ( $7 \mathrm{million} / \mathrm{ml}$ of seminal fluid), surgically treated 2 years ago for clinical grade III bilateral varicocele (according to Dubin's classification), was admitted to the Urology Department for suspected accidental surgical ligation of the left vas deferens. The patient underwent several diagnostic tests including phlebography of the left pampiniform plexus, bilateral vesico-deferentography. The steno-occlusion of the ejaculatory ducts was diagnosed, which was resolved through an innovative interventional radiology treatment.

Conclusions: Interventional radiology has played a decisive role in the diagnosis and treatment of the causes of male infertility. In our experience, it has considerable potential in the minimally invasive treatment of steno-obstructive pathologies of the vesico-deferential system.
\end{abstract}

Key words: interventional radiology; male infertility, vasography, scrotal ultrasound, varicocele, reproductive system.

\section{Introduction}

Infertility is a relatively common problem, affecting $15-20 \%$ of couples of reproductive age $[1,2]$. The male factor can be primary, or it can contribute to couple infertility in $40-60 \%$ of cases [3,4]. Male infertility can generally be divided into the following: pre-testicular, testicular, and post-testicular. The tests for the diagnosis are: spermiogram, the hormonal dosages ( $\mathrm{GnRh}, \mathrm{FSH}$, $\mathrm{LH}$, prolactin, total and free testosterone), the testicular volume, the testicular and peri-testicular structures, deferential system, and, in selected cases, testicular biopsy and retrograde vesico-deferentography [1]. We report an innovative treatment of interventional radiology in a 28-year-old male with oligospermia, already surgically treated for bilateral varicocele two years ago.

\section{Case presentation}

A 28-year-old man, surgically treated 2 years previously for clinical grade III bilateral varicocele (according to Dubin's classification) who had not conceived for 16 months despite regular and unprotected sexual intercourse, was admitted to the Urology Department for suspected accidental surgical ligation of the left vas deferens. The spermiogram exhibited showed moderate oligospermia ( 7 million/ml) without evidence of teratospermia and asthenospermia. The hormonal dosage of FSH, LH, $\mathrm{GnRH}$, prolactin, and total and free testosterone was normal. Liver, kidney, cardiological, and blood count tests were negative. The physical examination showed didymes and epididymes in place, not painful, and mobile. US confirmed the regular volume and echostructure of

Correspondence address:

Antonio Corvino, Department of Motor Science and Wellness, University of Naples “Parthenope”, via F. Acton 38, I-80133 Naples, Italy, e-mail: an.cor@hotmail.it

Authors' contribution:

A Study design · B Data collection · C Statistical analysis · D Data interpretation · E Manuscript preparation · F Literature search · G Funds collection 

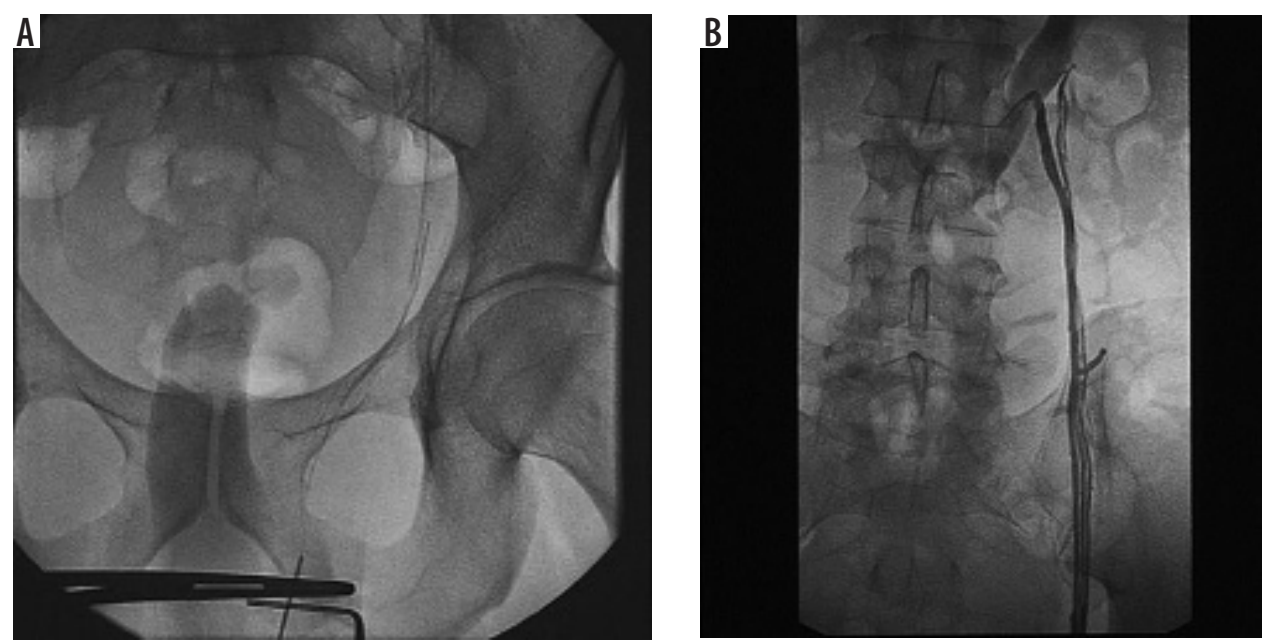

Figure 1. Left phlebography does not show recurrence of varicocele
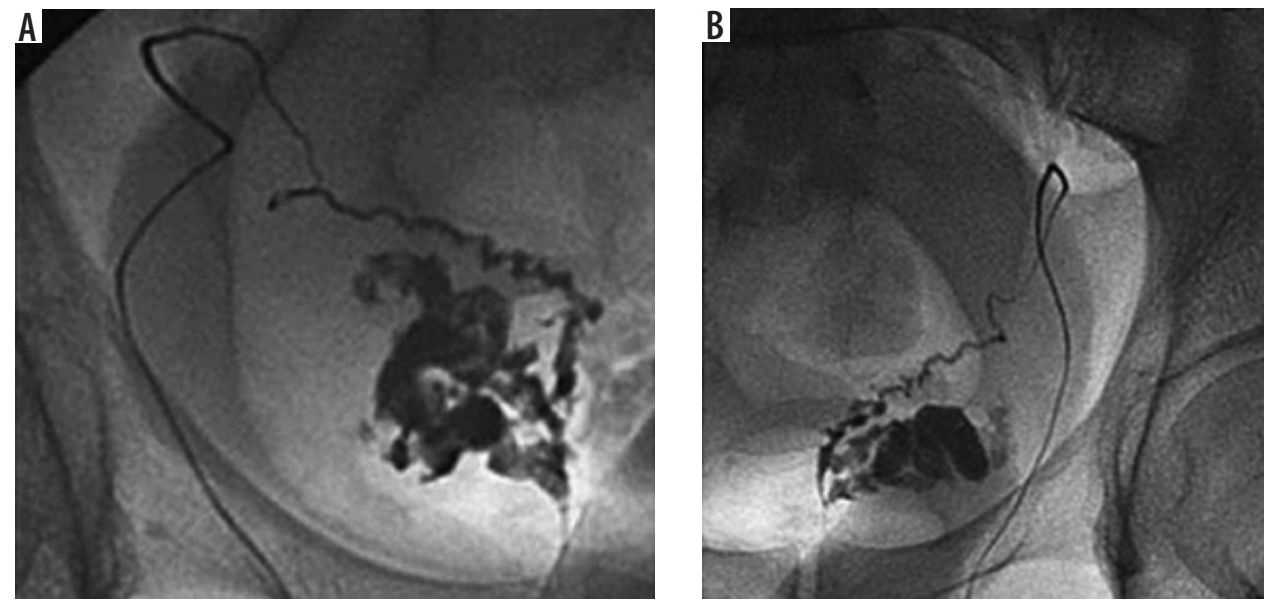

Figure 2. Bilateral deferent vesiculography showing dilation of the seminal vesicles caused by steno-occlusion of the ejaculatory ducts
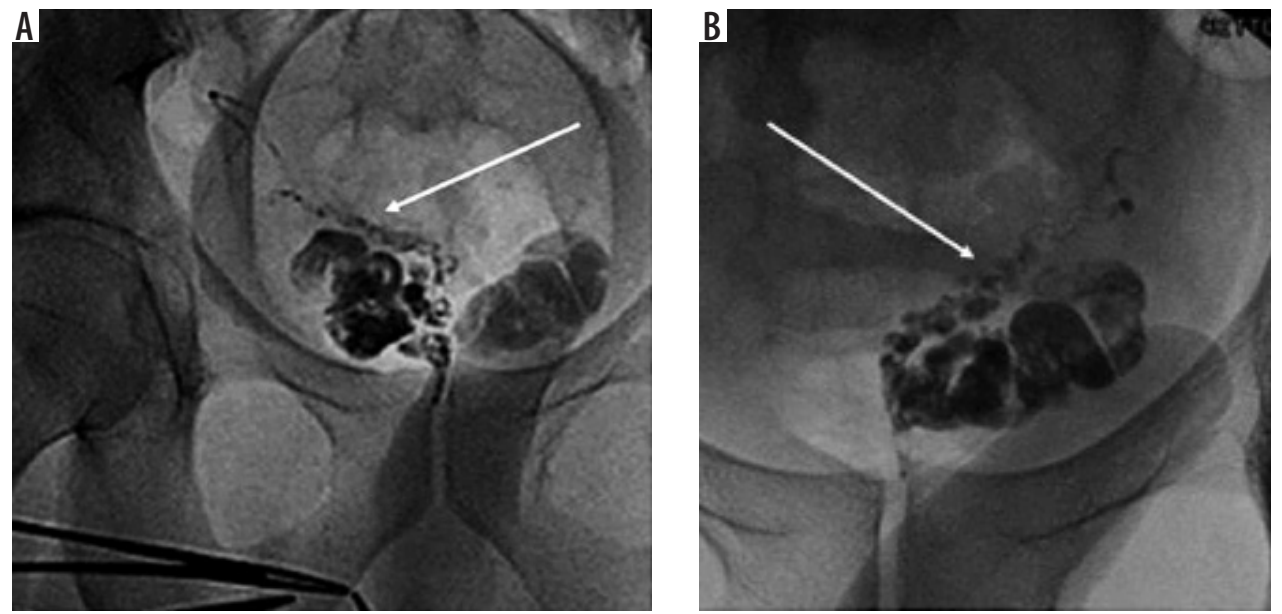

Figure 3. Gaseous insufflation of the seminal vesicles (arrow) is performed without success

didymes and epididymis. Scrotal tunics were not thickened. There was no hydrocele. The proximal deferens bilaterally were not delated. In colour Doppler, the intratesticular vascularization was regular. Pathological reflux was not observed after Valsalva test in the anterior pampiniform plexus bilaterally although residual ectasia of the venous calibre (d.a.p. $\max 3 \mathrm{~mm}$ ) was found especially on the left. In agreement with the urologist, we decided to perform a phlebography of the left pampiniform plexus, which confirmed the presence of the residual venous ectasia. Subsequently, bilateral vesico-deferentography was performed, which showed regular diameter, course, and patency of the vas deferens. The seminal vesicles were highly dilated, especially on the left due to stenoocclusion of the ejaculatory ducts; therefore, $\mathrm{H}_{2} \mathrm{O}$ gas insufflation was carried out with modest results, and the 
treatment was rescheduled. After 45 days, the patient exhibited a spermiogram, which showed severe oligospermia ( $1.5 \mathrm{million} / \mathrm{ml})$ without alterations in the shape and motility of the spermatozoa. In agreement with the urologist, we decided to perform a combined treatment. Preliminarily, urethroscopy was performed, thus identifying the verumontanum and then selectively catheterizing the ejaculatory ducts through micro-catheter and $\mathrm{H}_{2} \mathrm{O}$ insufflation was performed with complete unblocking of the orifices. The spermiogram performed at 90 days was negative with a sperm count of 50 million/ml. Currently the patient is in excellent clinical condition and undergoes ultrasound control and annual spermiogram.

\section{Discussion}

Successful male fertility requires normal spermatogenesis, complete epididymal maturation, normal sperm transport, and regular function of accessory glands. According to the latest World Health Organization guidelines (2010) oligozoospermia is defined as mild if the sperm concentration is $10-15 \mathrm{million} / \mathrm{ml}$ of semen, moderate if the sperm concentration is $5-10$ million/ $\mathrm{ml}$ of semen, and severe if the sperm concentration is $0-5 \mathrm{million} / \mathrm{ml}$ of semen [5]. The aetiologies of oligospermia or azoospermia are generally divided into 3 categories: pre-testicular, testicular, and post-testicular. Pre-testicular causes include endocrine abnormalities, which adversely affect spermatogenesis; it is also termed as secondary hypogonadism. The testicular causes, also called primary hypogonadism, are due to disorders of the spermatogenesis intrinsic to the testes. Finally, the post-testicular causes are due to dysfunction or obstruction of the passage of the sperm; this form is detected in about $40 \%$ of patients [6,7]. The aetiology of male infertility can be divided into obstructive and non-obstructive $[8,9]$. The causes of obstructive infertility are numerous and may be due to the pathology of the epididymis (cysts or nodules, idiopathic obstruction, inflammation, surgical complications), of the

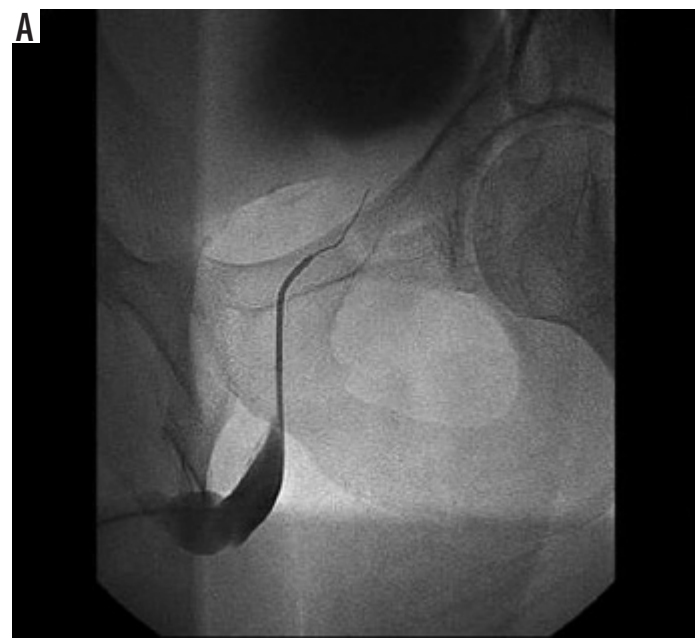

Figure 5. Trans-urethral recanalization of the left ejaculatory duct

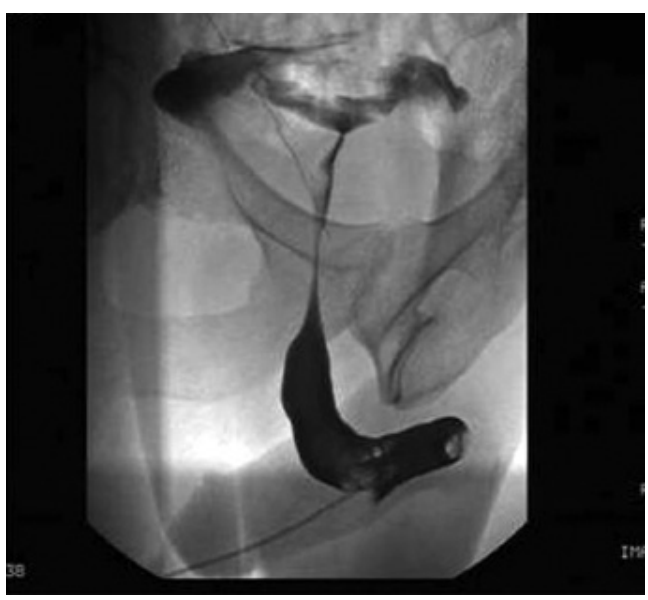

Figure 4. Retrograde urethrography showing the verumontanum and the ejaculatory ducts

deferens (surgical complications, hernia, idiopathic), and of the ejaculatory ducts (surgical complications, prostatic nodules, chronic inflammation, idiopathic). Non-obstructive pathology recognizes aetiology due to primary or secondary endocrinopathies, infections, testicular failure, ejaculation disorder, immunological causes, or primary or secondary varicocele.

Imaging helps to identify the cause of infertility and classify it as obstructive or non-obstructive [9]. The imaging modalities routinely used to evaluate the reproductive system in males include ultrasound (US), magnetic resonance imaging (MRI), and interventional techniques such as venography and vesico-deferentography $[10,11]$. The scrotal ultrasound examination is the first level investigation $[12,13]$. It is performed using a high-frequency linear transducer with the patient in the supine position. The examination allows the evaluation of the echostructure and the volume of the testes (normal value: 9-12.5 cc), the peri-testicular structures, and the proximal tract of the deferens [1-14]. Colour Doppler also allows the study of intra-testicular vascular flow and the study of reflux after Valsava test of the pampiniform plexus. Trans-rectal ultrasound (TRUS) allows the study of the distal genital tract,

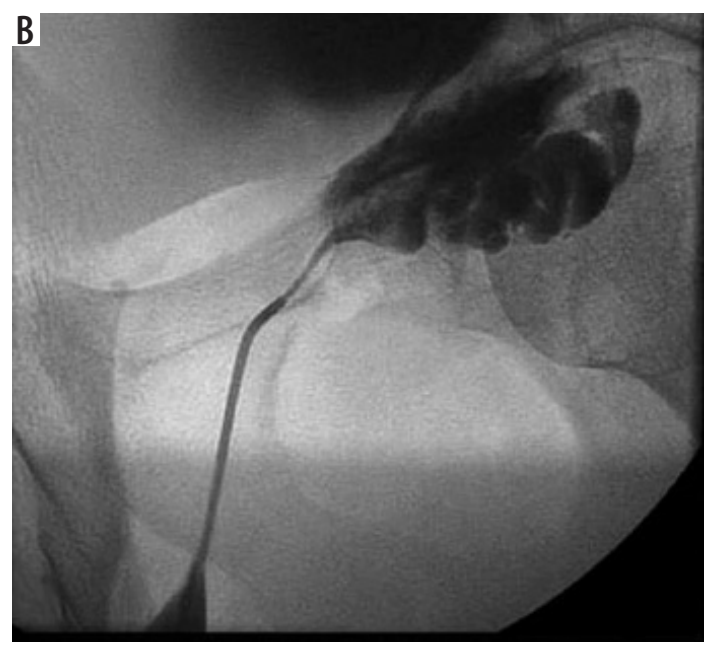


including the distal vas deferens, seminal vesicles (normal value d.a.p.: 8-15 mm), prostate, and ejaculatory ducts (normal value: $10-22 \mathrm{~mm}$ ) $[15,16]$. The CEUS allows the contrast study in cases of testicular and para-testicular incidental nodules [17]. MRI has excellent resolution of contrast and allows multiplanar reconstructions. It provides information on the entire male reproductive tract including the prostate, seminal vesicles, and ejaculatory ducts. Although it is considered an alternative to invasive radiology procedures $[18,19]$, vesiculo-deferentography is the gold standard in the study of the deferens, seminal vesicles, and ejaculatory ducts. The procedure consists of an ultrasound-guided puncture of the vas deferens, subsequent injection of contrast under X-ray scanning, and filling of the ducts until it leaks into the bladder, confirming its patency, calibre, and course [20,21]. Treatment of obstructive azoospermia is usually surgical and involves the recovery of sperm through TESE and microTESE techniques. The advantages of interventional vascular radiology that allows minimally invasive treatments of the genitourinary system are described in the literature
[22,23]; it allows the diagnosis and treatment of varicocele by endovascular scleroembolization [24]. However, there are no papers in the literature describing the treatment of obstructive oligozoospermia.

\section{Conclusions}

In our case, vesico-deferentography allowed a precise diagnosis of the stenosis point; the subsequent transurethral deferentography ensured the innovative minimally invasive treatment of the obstructive problem with an excellent final result and complete resolution of the oligospermia. Our experience suggests the great potential of radiological interventional treatment in steno-obstructive pathologies of the vesico-deferential system; however, it is essential to increase the number of cases treated.

\section{Conflict of interest}

The authors report no conflict of interest.

\section{Reference}

1. Sihag P, Tandon A, Pal R, et al. Sonography in male infertility: a look beyond the obvious. J Ultrasound 2018; 21: 265-276.

2. Boivin J, Bunting L, Collins JA, Nygren KG. International estimates of infertility prevalence and treatment seeking: potential need and demand for infertility medical care. Hum Reprod 2007; 22: 1506-1512.

3. World Health Organization. Towards more objectivity in diagnosis and management of male infertility. Int J Androl 1987; 7 (Suppl): $1-53$.

4. Gilbaugh JH 3rd, Lipshultz LI. Nonsurgical treatment of male infertility. An update. Urol Clin North Am 1994; 21: 531-548.

5. Cooper TG, Noonan E, Von Eckardstein S, et al. World Health Organization reference values for human semen characteristics. Hum Reprod Update 2010; 16: 231-245.

6. Inci K, Gunay LM. The role of varicocele treatment in the management of non-obstructive azoospermia. Clinics (Sao Paulo) 2013; 68 Suppl 1: 89-98.

7. Foresta C, Garolla A, Bettella A, Ferlin A, Rossato M, Candiani F. Doppler ultrasound of the testis in azoospermic subjects as a parameter of testicular function. Hum Reprod 1998; 13: 3090-3093.

8. Ammar T, Sidhu PS, Wilkins CJ. Male infertility: the role of imaging in diagnosis and management. Br J Radiol 2012; 85 (Special Issue 1): 59-68.

9. Cocuzza M, Alvarenga C, Pagani R. The epidemiology and etiology of azoospermia. Clinics 2013; 68 Suppl: 15-26.

10. Leaver RB. Male infertility: an overview of causes and treatment options. Br J Nurs 2016; 25: S35-S40.

11. Corvino A, Pignata S, Campanino MR, et al. Thyroglossal duct cysts and site-specific differential diagnoses: imaging findings with emphasis on ultrasound assessment. J Ultrasound 2020; 23: 139-149.

12. Catelli A, Ponsiglione A, Capaldo I, et al. Giant endometriod ovarian cancer: the role of dagnostic imaging and figo staging. EuroMediterranean Biomedical Journal 2020; 15: 94-96.
13. Corvino A, Setola SV, Sandomenico F, et al. Synchronous tumours detected during cancer patient staging: prevalence and patterns of occurrence in multidetector computed tomography. Pol J Radiol 2020; 85: e261-e270.

14. Kim W, Rosen MA, Langer JE, et al. US-MR imaging correlation in pathologic conditions of the scrotum. Radiographics 2007; 27: 1239-1253.

15. Kuligowska E, Fenlon HM. Transrectal US in male infertility: spectrum of findings and role in patient care. Radiology 1998; 207: 173-181.

16. Dudea SM, Ciurea A, Chiorean A, Botar-Jid C. Doppler applications in testicular and scrotal disease. Med Ultrason 2010; 12: 43-51.

17. Luzurier A, Maxwell F, Correas JM, et al. Qualitative and quantitative contrast-enhanced ultrasonography for the characterisation of non-palpable testicular tumours. Clin Radiol 2018; 73: 322.e1-322.e9.

18. Donkol RH. Imaging in male-factor obstructive infertility. World J Radiol 2010; 2: 172-179.

19. Raza SA, Jhaveri KS. Imaging in male infertility. Radiol Clin 2012; 50: 1183-1200.

20. d'Ancona CL, Netto NR, Stedile JAG, Billis A. Vasography: experimental study. Int Urol Nephrol 1989; 21: 73-79.

21. Solivetti FM, Drusco A, Pizzi G, et al. Percutaneous vesiculodeferentography in the diagnosis of male infertility: a review of our results and the data reported in the literature. J Ultrasound 2008; 11: 102-106.

22. Catelli A, Loiudice G, Corvino A, et al. Amplatzer vascular plug IV in the treatment of high flow renal arteriovenous fistula: case considerations. Radiol Case Rep 2020; 15: 1442-1445.

23. Catelli A, Loiudice G, Corvino A, et al. Amplatzer vascular plug in renal artery embolization: case report and review of the literature. Egyptian Journal of Radiology and Nuclear Medicine 2020; 51: 158.

24. Paisant-Thouveny F, Le Pennec V, Loffroy R. Varicoceles, pelvic varices and pelvic congestion syndrome: Interventional radiology in diagnosis and treatment. Presse Med 2019; 48: 419-434 [Article in French]. 